\title{
Lymphatic Drainage of the Breast: from Theory to Surgical Practice
}

\author{
Drenaje Linfático de la Mama: desde la Teoría a la Práctica Quirúrgica
}

\author{
"José Humberto Tavares Guerreiro Fregnani \& ** José Rafael Macéa
}

FREGNANI, J. H. T. G. \& MACÉA, J. R. Lymphatic drainage of the breast: from theory to surgical practice. Int. J. Morphol., 27(3):873-878, 2009.

SUMMARY: Until recently, complete removal of axillary lymph nodes was performed as part of the treatment of breast cancer. Sentinel lymph node biopsy (SLNB) in selected cases has reduced the number of cases of wide axillary dissection and the related morbidity. Knowledge of breast lymphatic drainage is essential for understanding the principles behind SLNB and also for performing safe and correct axillary lymphonodectomy. This paper describes in detail the anatomical issues relating to breast lymphatic drainage and the correlated axillary and extra-axillary lymph nodes. In addition, it shows the application of this theoretical knowledge to surgical practice, especially with regard to SLNB and lymphonodectomy. The surgical nomenclature is compared with the current International Anatomical Terminology.

KEY WORDS: Lymphatic drainage, Sentinel lymph node biopsy, Breast cancer.

\section{INTRODUCTION}

Breast cancer is the most frequent type of tumor among women, accounting for approximately one quarter of all tumors in women. It has been estimated that more than one million new cases occur worldwide annually. Breast cancer is responsible for significant morbidity and mortality (Parkin \& Fernandez, 2006; Gospodarowicz et al., 2006).

The involvement of axillary lymph nodes is the main prognostic factor in breast tumors in their early clinical stages (Gospodarowicz et al.). Despite all the progress in subsidiary tests, histopathological examination of axillary lymph nodes is still the most accurate method for assessing lymph node status. Until recently, this was routinely carried out by complete surgical removal of axillary lymph nodes (lymphadenectomy). However, many women without metastasis were unnecessarily undergoing lymphadenectomy. They were thus becoming liable to suffer from the complications that are inherent to this surgical procedure, such as: axillary fluid accumulations (lymphocele), pain, infection, shoulder mobility restriction, lymphedema, changes to the sensitivity of the upper limb, posterior scapular dislocation (winged scapula syndrome), brachial plexus lesions, axillary vessel thrombosis and lesions, skin necrosis and pectoral muscle atrophy, among others (Torresan et al., 2002; Kim et al., 2006).

Applying the sentinel lymph node concept to breast cancer has brought a significant reduction in the number of comprehensive axillary dissections, thereby leading to reduced postoperative morbidity and better quality of life for such patients (McCready et al., 2005). According to the most recent consensus drawn up by societies connected to the Brazilian Medical Association, biopsy of the sentinel lymph node in breast cancer cases is indicated when there is in situ ductal carcinoma showing comedonecrosis or high-grade carcinoma, and when there is invasive carcinoma with a diameter less than $3 \mathrm{~cm}$, without clinical involvement of the axillae or breast skin. In other cases of invasive tumors, comprehensive dissection and axillary lymph node removal (lymphadenectomy) must be carried out (Quadros \& Gebrim, 2007).

\footnotetext{
"Assistant Professor in the Morphology Department, School of Medical Sciences, Santa Casa de São Paulo. PhD from Antônio Prudente Foundation Treatment and Research Center of the A. C. Camargo Cancer Hospital (São Paulo, Brazil).

** Adjunct Professor and Head of the Morphology Department, School of Medical Sciences, Santa Casa de São Paulo. PhD from the School of Medical Sciences, Santa Casa de São Paulo (São Paulo, Brazil).
} 
The present study had the aim of discussing the application of theoretical knowledge of breast lymphatic drainage, particularly with regard to sentinel lymph node investigations and axillary lymphadenectomy. The current nomenclature used by surgeons to describe lymph nodes is also discussed based on the international anatomical terminology proposed by the Federative Committee on Anatomical Terminology (SBA, 2001).

\section{BREAST LYMPHATIC DRAINAGE}

There are four classically described intercommunicating lymphatic plexi in the breast: two superficial and two deep ones. The superficial plexi are located in the dermis (cutaneous plexus) and in the superficial subcutaneous region (subcutaneous plexus). One of the deep plexi is located in the pectoralis major muscle fascia (fascial plexus) and the other is in the mammary gland, including lobes and ducts (glandular plexus). Thelatter, through lymphatic vessels that accompany the lactiferous ducts, communicates with a region of the subcutaneous plexus located immediately below the areolas, known as the subareolar plexus (Sappey's). The fascial plexus communicates with the subcutaneous plexus through lymphatic vessels along the fibrous fasciculi of the stroma. Less frequently, the breast lymphatic vessels may also drain to the lymphatic plexus of the liver and subdiaphragmatic plexi, through abdominal wall vessels (Gerota's paramammary route). Anatomical studies have shown that the density of lymphatic vessels in superficial plexi is higher than the density in the deep plexi (Tanis et al., 2001; Macéa \& Fregnani, 2006).

In the nineteenth century, based on results from mercury injections into lymphatic vessels, Sappey postulated that all breast lymph would initially drain to the subareolar plexus and, after passing through it, would continue to the axillary lymph nodes. Subsequent studies showed that Sappey was not completely right, since there are other routes for lymph drainage. It is now known that the drainage takes place through lateral and medial efferent lymphatic vessels that lead directly and preferentially towards the axillary lymph nodes or the lymph nodes along the internal thoracic vessels (Tanis et al.).

The superficial plexi drain directly to the axillary lymph nodes. The deep plexi also drain to the axillae, but may initially drain into intramammary and interpectoral lymph nodes. Breast lymphatic drainage may occur into parasternal lymph nodes ("internal mammary" lymph nodes), although this drainage pattern is almost exclusive to the deep lymphatic plexi. Occasionally, the lymphatic vessels may follow along the cutaneous branches of intercostal vessels towards the posterior intercostal lymph nodes, which are located near the rib heads. From there, the lymph continues towards the thoracic duct. The superficial lymphatic vessels that are located more cranially in the breast may continue to cervical lymph nodes, i.e. to the supraclavicular lymph nodes (Tanis et al.; Macéa \& Fregnani).

The axillary lymph nodes are the main group for breast lymphatic drainage and consequently they are the main location for metastasis. Removal of the axillary lymph nodes is part of the surgical treatment for breast cancer, since they have an important role in staging and regionally controlling the disease (Lyman et al., 2005). Hence, detailed knowledge of this lymph node group is important. However, breast lymph is received not only by the axillary lymph nodes but also by other extra-axillary lymph nodes (parasternal, interpectoral, deltopectoral, supraclavicular and posterior intercostal lymph nodes).

A detailed review on breast lymphatic drainage and axillary lymph nodes can be found in a paper published previously in the International Journal of Morphology (Macéa \& Fregnani).

\section{FROM THEORY TO PRACTICE}

Regarding sentinel lymph nodes. By definition, a sentinel lymph node is the first one to receive the lymphatic drainage from an organ and consequently it is the first one to be affected by the presence of metastatic cells coming from a neoplasm, particularly carcinomas. In the case of breasts, the sentinel lymph node is usually located in the group of axillary lymph nodes. In women with breast cancer, it is crucial to find it in order to define whether there is a need for lymphadenectomy in cases in which there is no clinically detectable metastasis in the axillary lymph nodes (NCCN, 2007). When the axillary sentinel lymph node is affected by metastasis, other axillary lymph nodes are also affected in about half of the cases, and this is an indication of the need to perform lymphadenectomy. On the other hand, absence of metastasis in the sentinel lymph node avoids the need for axillary lymphadenectomy and its morbid consequences. Doubts remain regarding the procedure to be carried out when the sentinel lymph node is not located in the axilla but, rather, in the parasternal lymph nodes ("internal mammary" lymph nodes). Theoretically, and until proven otherwise, the only women who would benefit from a biopsy on the parasternal sentinel lymph node would be those without an indication for adjuvant chemotherapy. Even in the occasional cases in which the sentinel parasternal lymph node is affected by metastasis, the American Society of Clinical Oncology does not recommend radical dissection 
of this lymph node group, since this procedure does not bring additional benefit to survival (Lyman et al.).

Regarding the capacity of the sentinel lymph node to predict the status of axillary lymph nodes, the method has $96 \%$ accuracy, a false negative rate of less than 5 to $10 \%$ and a negative predictive value of more than $95 \%$ (Pater \& Parulekar, 2006).

The understanding of the technique used for identifying the sentinel lymph node is dependent upon knowledge of breast lymphatic drainage. The technique is based on injection of radiotracer and/or contrast. The radiotracer (technetium $99 \mathrm{~m}$ ) is injected up to 24 hours before the procedure and is concentrated on the sentinel lymph node. The radiation emitted by this lymph node is captured by a sensitive probe during the surgical procedure (gamma probe). The method is more accurate if contrast is injected a few minutes prior to surgery, since this will flow through the lymphatic vessels and temporarily accumulate in the sentinel lymph node, thus coloring the vessels and the lymph node (Kim et al.). The contrasts most used are patent blue and isosulfan blue. Methylene blue must be avoided because of its faster diffusion through the lymphatic vessels and lymph nodes, thereby coloring them for a shorter period (Quadros \& Gebrim). It is recommended that, after injection, light massage should be performed on the puncture area for 5 to 10 minutes, in order to increase the pressure on the lymphatic plexi, thus facilitating the radiotracer and contrast drainage. This method seems to be safe, since side effects from the radiotracer and contrast are rare, with estimated allergic reaction rates of less than $2 \%$ and anaphylaxis of less than $1 \%$. As yet, there are no records of side effects relating to the radiation emitted by the radiotracer (Pater \& Parulekar).

The radiotracer and contrast injection for sentinel lymph node biopsy is performed either on the breast surface or at the depth of this lymph node. The superficial injection technique may be performed intradermally or subcutaneously (just above the tumor), periareolarly or subareolarly. In the deep injection technique, the injection is made into the peritumoral area, or inside the tumor. The superficial injection techniques are based upon the fact that both the gland and the skin have a common embryonic origin and therefore share the same lymphatic drainage (Tanis et al.; Quadros \& Gebrim). This has been proven in studies finding complete agreement between the intradermal contrast injection and the deep injection (peritumoral) (Rubio \& Klimberg, 2001; Tanis et al.). Since drainage to the parasternal lymph nodes is almost exclusive to the deep plexi in the breast, it is rare to identify a sentinel in this group of lymph nodes using a superficial injection. On the other hand, intratumoral or peritumoral injections may lead to identification of a sentinel lymph node along the internal thoracic vessels in up to $30 \%$ of the cases (Tanis et al.; Buchpiguel, 2004).

Some surgeons have used a technique of only injecting contrast a few minutes prior to surgery, without using a radiotracer. It must be considered that sentinel lymph nodes located outside the axillae will not be detected through this technique without radiotracer. Therefore, it is important to use the combined method for identifying the sentinel lymph node.

Considering that the density of the lymphatic vessels is significantly higher in the superficial plexi of the breast than in the deep plexi, the radiotracer and contrast will flow more rapidly between the injection site and the sentinel lymph node when the injection is given superficially. More frequently, the lymphatic vessels leaving the breast are clearly marked by the contrast when the injection is superficial, which helps considerably in identifying the sentinel lymph node. Apart from the injection site, other factors may also interfere with the lymphatic drainage, such as the state of hydration and the use of certain anesthetic drugs. Dehydrated patients, or those undergoing anesthesia with halothane, present significantly decreased lymphatic flow, which may make it more difficult to identify the sentinel lymph node during surgery (Tanis et al.).

With regard to the radiotracer, there is a technical detail that directly interferes with the speed of propagation through lymphatic vessels and with the concentration in the sentinel lymph node. For the radiotracer to be injected, it necessarily must be attached to a particle of organic or inorganic nature. The size of this particle is the determinant for the speed with which the radiotracer flows through the lymphatic vessels and the concentration in the lymph nodes. Table 1 shows a list of a few particles that are attached to technetium and used for locating the sentinel lymph node, including the particle sizes.

Small particles such as antimony trisulfide pass rapidly into the lumen of lymphatic capillaries and are quickly transported to the sentinel lymph node. However, because of their small diameter, these particles pass rapidly through the interior of the organ without being phagocytized and continue onwards to the next lymph node. This gives rise to reduced radiotracer concentration in the sentinel lymph node and also the labeling of additional lymph nodes that are not strictly sentinel lymph nodes. On the other hand, large particles such as non-filtered colloidal sulfur have the disadvantage of entering more slowly into the lymphatic capillaries, although they achieve higher concentrations in the sentinel lymph node. It is believed that particles of diameters between 10 and $100 \mathrm{~nm}$ are ideal for biopsies on sentinel lymph nodes (Tanis et al.). 
The amount of radiotracer and contrast to be injected is a matter of discussion in the literature, ranging from volumes as small as $0.2 \mathrm{ml}$ up to large volumes like $16 \mathrm{ml}$. According to the opinion of those who recommend injections with small volumes, the low pressure in the lymphatic capillaries would not significantly change the lymph flow and therefore there would be a lower possibility of labeling a false sentinel lymph node. On the other hand, those who defend the idea of injections with larger volumes have the aim of increasing the flow in the lymphatic vessels, thereby improving the chance of lymph node identification. In fact, the rates of sentinel lymph node identification are similar with either of the two methods. It is now recommended that a radiotracer injection of between 4 and $8 \mathrm{ml}$ should be administered for preoperative lymphoscintigraphy, while the same additional volume should be used for the contrast injection immediately prior to surgery (Tanis et al.).

Regarding axillary lymphadenectomy. As mentioned above, the presence of metastasis in the sentinel lymph node removed from the axilla is a formal indication for lymphadenectomy (NCCN). For this, the surgeon needs to have profound knowledge of the regional anatomy and adequate training in order to avoid accidental damage to vessels and nerves.

Mastologists and oncological surgeons traditionally divide the axillary lymph nodes into levels I, II and III, also known respectively as the low, medium and apical axilla. This division is based upon the topographic relationship between the lymph nodes and the pectoralis minor muscle. Level I lymph nodes are located laterally to the lateral margin of the pectoralis minor muscle; level II lymph nodes are located posteriorly to this muscle; and level III lymph nodes are located medially to the medial margin of the muscle (Greene et al., 2002). However, the Federative Committee on Anatomical Terminology does not recognize this classification in the International Anatomical Terminology (SBA).

It is of interest for the surgeon to be able to establish adequate correspondence between the surgical levels of the lymph nodes and the anatomy. From an anatomical point of view, level I lymph nodes include the pectoral (anterior), subscapular (posterior) and humeral (lateral) axillary lymph nodes. Level II lymph nodes are the central ones and possibly some apical lymph nodes (Macéa \& Fregnani). According to the concept of the American Joint Committee on Cancer, interpectoral lymph nodes (Rotter's) are also considered to be axillary lymph nodes and should be grouped in level II (Greene et al.). It needs to be borne in mind that, according to the anatomy, this is an equivocal concept, since interpectoral lymph nodes are not strictly axillary ones (SBA). Finally, level III lymph nodes include the majority of apical axillary lymph nodes (Macéa \& Fregnani). Table II summarizes the correlations described previously.

In most cases, dissemination of neoplastic cells from the breast towards the axilla is done sequentially, initially affecting level I, then level II and lastly, level III lymph nodes (Luini et al., 2005).

The surgeon needs to be aware of the possibility of damage to nerves and vessels during the dissection of axillary lymph nodes. When dissecting pectoral axillary lymph nodes (anterior), located along the lateral thoracic vessels, it is common to section the intercostobrachial nerve close to the second intercostal space. This nerve corresponds to the lateral cutaneous branch of the second intercostal nerve, which emerges from the lateral thoracic wall on the medial axillary line, around $2 \mathrm{~cm}$ anteriorly to the long thoracic nerve (Torresan et al.; Macéa \& Fregnani). Because this is a sensitive nerve, the damage caused by sectioning it will only consist of hypoesthesia in the skin covering the axilla and the medial region of the arm. There is often an additional intercostobrachial nerve in the third intercostal area, which is also frequently sectioned. After removing this group of lymph nodes, the dissection usually continues posteriorly, along the thoracic wall. Inattentiveness may lead to damage to the long thoracic nerve (Bell's). This nerve is attached to the thoracic wall and is located more posteriorly in relation to the lateral thoracic vessels. It is frequently dislodged from its bed when the anterior serrate muscle fascia is removed. This will result in adherence of the nerve to the product from lymph node dissection. If this situation is not noticed, it may give rise to nerve sectioning and consequent denervation of the anterior serrate muscle, thus leading to posterior dislocation of the scapula ("winged scapula" syndrome) (Drake et al., 2006; Macéa \& Fregnani; Moore \& Dalley, 2006).

During dissection of the subscapular axillary lymph nodes (posterior), damage may occur to the thoracodorsal, superior subscapular and inferior subscapular nerves. The thoracodorsal nerve is responsible for the innervation of the latissimus dorsi muscle and it runs close to the subscapular and thoracodorsal vessels. It may be damaged when the vessels are also sectioned. If ligature of these vessels is necessary, this procedure must be performed with great care, making sure the nerve is isolated and is not included in the ligature. The superior and inferior subscapular nerves are located over the subscapular muscle, respectively medially and laterally to the thoracodorsal vessel-nerve bundle. The first is located deeply, close to 
the angle formed between the thoracic wall and the scapula, while the second is located close to the lateral border of the scapula. They both innervate the subscapular muscle, but the inferior is also responsible for innervation of the teres major muscle. These nerves may suffer damage when the subscapular muscle fascia is extracted and the dissection area expends posteriorly to the axillary vein, or superolaterally to the latissimus dorsi muscle (Drake et al.; Macéa \& Fregnani; Moore \& Dalley).

To dissect the central and apical axillary lymph node group, the pectoralis minor muscle needs to be displaced or sectioned. If this maneuver is performed roughly, there may be bleeding from the thoracoacromial artery or its branches, which are laid out medially to the medial margin of the pectoralis minor muscle. In addition, there may also be injury to the lateral pectoral nerve, which accompanies the thoracoacromial artery and its pectoral branch. Lesion of the medial pectoral nerve is certain to occur when the pectoralis minor muscle is extracted, since this nerve perforates the muscle along its pathway. During displacement or sectioning of the pectoralis minor muscle, it is also important to pay attention to the cephalic vein,

Table I. Particles aggregated to technetium that are used for investigating sentinel lymph nodes, and their respective sizes. Source: Buchpiguel, 2004.

\begin{tabular}{lc}
\hline Particle & Size (nm) \\
\hline Non-filtered colloidal sulfur & $5-5.000$ \\
Filtered colloidal sulfur & $100-200$ \\
Antimony trisulfide & $5-15$ \\
Nanocolloid & $5-80$ \\
Albumin microcolloid & $200-2.000$ \\
Dextran & $2-4$ \\
Phytate & $10-50$
\end{tabular}

Table II. Surgical levels of axillary lymph nodes according to the American Joint Committee on Cancer and their anatomical correspondence. * Although the American Joint Committee on Cancer considers them to be axillary lymph nodes, they are not so from an anatomical point of view.

\begin{tabular}{cl}
\hline Surgical level & Anatomical correspondence \\
\hline I & Pectoral axillary lymph nodes (anterior) \\
& Subscapular axillary lymph nodes (posterior) \\
& Humeral axillary lymph nodes (lateral) \\
II & Central axillary lymph nodes \\
& Some apical axillary lymph nodes \\
& Interpectoral lymph nodes (Rotter's) \\
III & Apical axillary lymph nodes \\
\hline
\end{tabular}

which after anteriorly passing the muscle tendon and crossing its medial margin, posteriorly curves to drain into the axillary vein. Excessive traction of the cephalic vein may lead to its disconnection from the axillary vein, thereby causing intense bleeding that is difficult to control (Drake et al.; Macéa \& Fregnani; Moore \& Dalley).

To dissect deeper lymph nodes (central and apical), the surgeon again needs to be aware of the long thoracic nerve (Bell's). This nerve emerges from the ventral primary branches of the spinal nerves $\mathrm{C} 5, \mathrm{C} 6$ and $\mathrm{C} 7$ and posteriorly follows the brachial plexus and axillary vessels. If the surgeon is inattentive, the nerve may be sectioned while removing the adipose tissue that covers the lower surface of the axillary vein. In addition, apical lymph node dissection requires extra care so that there is no accidental damage to the superior thoracic artery, which is a small branch of the axillary artery along the upper lateral thoracic wall, towards which it heads (Drake et al.; Macéa \& Fregnani; Moore \& Dalley).

By respecting the axillary vein as the most cranial limit of the lymph nodes dissection area, the axillary artery and the different fasciculi and branches of the brachial plexus will be protected against accidental lesions. In the axilla, the artery is always placed in a lateral (cranial) position in relation to the vein and therefore may be damaged when axillary lymph nodes dissection goes beyond the upper limit of the axillary artery. Since all the fasciculi of the brachial plexus in level III are in a lateral (cranial) position in relation to the axillary vessels, excessive cranial dissection may lead to damage to any of them. In level II, the medial and lateral fasciculi are more susceptible to injury, while the posterior fasciculus is protected by the axillary artery, which is located anteriorly to it. In level I, the roots of the median nerve are located anteriorly to the axillary artery and will be damaged if the lymph node dissection goes beyond the limit (Drake et al.; Macéa \& Fregnani; Moore \& Dalley).

\section{CONCLUSION}

Sentinel lymph node biopsy has brought benefits to breast cancer patients, through avoiding unnecessary axillary lymphadenectomy and its subsequent morbidity. However, a good grounding in anatomical knowledge of the lymphatic drainage plexi of the breasts is required, along with knowledge of the related lymph nodes. This is essential for understanding the principles governing biopsies of sentinel lymph nodes and also for performing axillary lymphadenectomy adequately, with regard to technique and safety. 
FREGNANI, J. H. T. G. \& MACÉA, J. R. Drenaje linfático de la mama: desde la teoría a la práctica quirúrgica. Int. J. Morphol., 27(3):873-878, 2009.

RESUMEN: Hasta hace poco, la eliminación completa de los linfondos axilares se realizaba como parte del tratamiento del cáncer de mama. En casos seleccionados la biopsia del linfonofo centinela ha reducido el número de casos de disección axilar y la morbilidad. El conocimiento del drenaje linfático de la mama es esencial para comprender los principios detrás del SNLB y también para la realización segura y correcta de la linfonodectomía axilar. Este trabajo describe en detalles los aspectos anatómicos en relación a la lactancia y correlaciona el drenaje linfático axilar y linfonofos extra-axilares. Además, se muestra la aplicación de estos conocimientos teóricos en la práctica quirúrgica, sobre todo con respecto al linfonofo centinela y la linfonodectomía. La nomenclatura quirúrgica es comparada con la actual Terminología Anatómica Internacional.

PALABRAS CLAVE: drenaje linfático, la biopsia del ganglio centinela, cáncer de mama.

\section{REFERENCES}

Buchpiguel, C. A. Controvérsias e avanços técnicos na detecção do linfonodo sentinela. Radiol. Brasil., 37(4):III-V, 2004.

Drake, R. L.; Vogl, W. \& Mitchell, A. W. Gray's anatomia para o estudante. Rio de Janeiro, Elsevier, 2006.

Gospodarowicz, M. K.; O'Sullivan, B. \& Sobin, L. H. Prognostic Factors in Cancer. $3^{\text {rd }}$ ed. New York, Wiley, 2006.

Greene, F. L.; Page, D. L.; Fleming, I. D.; Fritz, A. G. \& Balch, C. M. AJCC Cancer staging handbook. $6^{\text {th }}$ ed. New York, Springer-Verlag, 2002.

Kim, T.; Giuliano, A. E. \& Lyman, G. H. Lymphatic mapping and sentinel lymph node biopsy in early-stage breast carcinoma: a meta-analysis. Cancer, 106:4-16, 2006.

Luini, A.; Gatti, G.; Ballardini, B.; Zurrida, S.; Galimberti, V.; Veronesi, P.; Vento, A. R.; Monti, S.; Viale, G.; Paganelli, G. \& Veronesi, U. Development of axillary surgery in breast cancer. Ann. Oncol., 16(2):259-62, 2005.

Lyman, G. H.; Giuliano, A. E.; Somerfield, M. R.; Benson, A. B. 3rd.; Bodurka, D. C.; Burstein, H. J.; Cochran, A. J.; Cody, H. S. 3rd.; Edge, S. B.; Galper, S.; Hayman, J. A.; Kim, T. Y.; Perkins, C. L.; Podoloff, D. A.; Sivasubramaniam, V. H.; Turner, R. R.; Wahl, R.; Weaver, D. L.; Wolff, A. C.; Winer, E. P. \& American Society of Clinical Oncology. American Society of Clinical Oncology guideline recommendations for sentinel lymph node biopsy in early-stage breast cancer. J. Clin. Oncol., 23:7703-20, 2005.

Macéa, J. R. \& Fregnani, J. H. T. G. Anatomy of the thoracic wall, axilla and breast. Int. J. Morphol., 24(4):691-704, 2006.

McCready, D.; Holloway, C.; Shelley, W.; Down, N.; Robinson, P.; Sinclair, S.; Mirsky, D. \& Breast Cancer Disease Site Group of Cancer Care; Ontario's Program in Evidence-Based Care. Surgical management of early stage invasive breast cancer: a practice guideline. Can. J. Surg., 48:185-94, 2005.
Moore, K. L. \& Dalley, A. F. Anatomia orientada para a clínica. Rio de Janeiro, Guanabara-Koogan, 2006.

NCCN (Natinonal Comprehensive Cancer Network). NCCN Clinical Practice Guidelines in Oncology. Breast Cancer, 2007. Disponible en: http://www.nccn.org/professionals/ physician_gls/PDF/breast.pdf

Parkin, D. M. \& Fernandez, L. M. Use of statistics to assess the global burden of breast cancer. Breast J., 12(1):S70-80, 2006.

Pater, J. \& Parulekar, W. Sentinel lymph node biopsy in early breast cancer: has its time come? J. Natl. Cancer Inst., 98:568-9, 2006.

Quadros, L. G. \& Gebrim, L. H. A pesquisa do linfonodo sentinela para o câncer de mama na prática clínica do ginecologista brasileiro. Rev. Bras. Ginecol. Obstet., 29:158-64, 2007.

Rubio, I. T. \& Klimberg, V. S. Techniques of sentinel lymph node biopsy. Semin. Surg. Oncol., 20:214-23, 2001.

SBA (Sociedade Brasileira de Anatomia). Terminología Anatômica. Terminologia Anatômica Internacional. $1^{\text {a }}$ edição. São Paulo, Manole, 2001.

Tanis, P. J.; Nieweg, O. E.; Valdes Olmos, R. A. \& Kroon, B. B. Anatomy and physiology of lymphatic drainage of the breast from the perspective of sentinel node biopsy. J. Am. Coll. Surg., 192:399-409, 2001.

Torresan, R. Z.; Santos, C. C.; Conde, D. M. \& Brenelli, H. B. Preservação do nervo intercostobraquial na linfadenectomia axilar por carcinoma de mama. Rev. Bras. Ginecol. Obstet., 24:221-6, 2002.

\section{Correspondence to:}

José Rafael Macéa

Departamento de Morfologia

Faculdade de Ciências Médicas da Santa Casa de São Paulo

Rua Dr. Cesário Motta Júnior, n 61 - CEP 01221-020

São Paulo (SP), BRAZIL.

E-mail: jrmacea@hotmail.com mdfregnani@terra.com.br

Received: 17-09-2008

Accepted: 29-01-2009 